\title{
LITERATURA E MÚSICA: UM ENCONTRO POSSÍVEL NA ESCOLA
}

\section{LITERATURE AND MUSIC: A POSSIBLE ENCOUNTER AT SCHOOL}

\author{
Juliana Alves Menezes ${ }^{1}$ \\ Everton Luis Paulino Vinha²
}

\begin{abstract}
Resumo: O objetivo do artigo é apresentar uma prática do ensino de literatura, no Ensino Fundamental II, em duas turmas de $6^{\circ}$ anos de uma escola particular da cidade de Maringá, noroeste do Paraná. Os resultados revelaram que é possível atender ao gosto do aluno e levá-los a se aproximarem dos textos literários, porém ao docente cabe o papel de compreender o seu alunado como leitores contemporâneos.
\end{abstract}

\begin{abstract}
The objective of this study is to present a practice of literary teaching, in Elementary School II, 6th year of a private school in the city of Maringá, northwest of Paraná, Brazil. The results show that it is possible to meet the student's taste and get them closer to literary texts; however, the teacher is responsible for understanding his students as contemporary readers.
\end{abstract}

Palavras-chave: Ensino de literatura; Prática literária; Literatura e outras artes; Formação literária.

Keywords: Literature teaching ; Literary practice; Literature and other arts; Literary formation.

\section{Introdução}

Este artigo tem como objetivo apresentar uma prática do ensino de literatura que foi aplicada nos $6^{\circ}$ anos de uma escola particular em Maringá, no noroeste do estado do Paraná. Tal prática foi construída de modo que a aproximação entre a Literatura e Outras Artes, especificamente, a música, colaborasse na aproximação do gosto do aluno aos conteúdos apresentados na escola. Um dos maiores desafios, hoje, no que diz respeito ao ensino de literatura, é o de como despertar no aluno o gosto pela leitura de textos literários?

A perda do gosto pela leitura, pelo estudo e pela reflexão são impasses que a escola tem enfrentado. Como mobilizar num aluno, a cada dia, mais virtual, o interesse pela leitura do impresso e da literatura?

Segundo Candido (1989), a literatura confirma e nega, propõe e denuncia, apoia e combate, fornecendo a possibilidade de vivermos dialeticamente os problemas. Por isso, a arte literária é indispensável na formação da personalidade, das emoções, das expressões, da reflexão, da aquisição do saber, da percepção da complexidade do mundo, da criatividade, da criticidade de um indivíduo,

1 Doutora em Letras pela Universidade Estadual Paulista (UNESP).

2 Graduado em Letras pela Universidade Estadual de Maringá (UEM). 
desenvolvendo em nós a quota de humanidade na medida em que nos torna mais compreensivos e abertos para a natureza, a sociedade e o semelhante (CANDIDO, 1989, p. 117).

Desse modo, o artigo emerge da iminente necessidade de um maior conhecimento da literatura enquanto obra de arte, construída e constituída por técnicas de escritura com valor estético e, principalmente, pela compreensão de que, enquanto obra de arte, ela se constituiu como valioso instrumento para a compreensão do seu mundo interno e do seu mundo externo. Justifica-se o interesse em tratar dessa temática a partir do partilhamento de práticas que consigam mediar a leitura literária, tendo em vista a formação de leitores anárquicos que, mesmo vivendo num mundo caótico, vazio, rápido e hipócrita, terminam por encontrar alguns momentos de sensibilização, assim o ensino de literatura torna-se vivo e, também, um espaço de aconchego, de colo, de acolhimento e de humanização (MENEZES, 2019, p. 54)

Desde a década de 80 , as pesquisas na área de literatura e ensino apontam para os motivos que levam os jovens a se distanciarem da literatura escolarizada (ROCCO, 1981; VIEIRA, 1990; LEAHYDIOS, 1995; CEREJA, 2005; RODELLA, 2008; MENEZES, 2008). Tais pesquisas apontam que a ausência de um percurso no momento da aula, a falta de preocupação docente com a expectativa dos alunos, o trabalho com fragmentos de textos, a reprodução apenas da voz do material didático, a metodologia falha ou a ausência da metodologia, o ensino transmissivo da literatura, em razão de, muitas vezes, o próprio professor não ser leitor ou do cumprimento de programas de concursos vestibulares com suas listas de obras são alguns dos fatores responsáveis pelo distanciamento do gosto do aluno da literatura ensinada na escola.

Educar para formar leitores é algo que desperta não apenas conhecimentos específicos, mas também uma sensibilidade que permite o questionamento do mundo e o desejo de mudança da condição de mediocridade à que o ser humano é submetido. Sem a literatura, as pessoas tornam-se mais passíveis de conformismo com situações de injustiça cometidas por outrem, e, justamente, por isso ela questiona o posicionamento de discursos autoritários como, por exemplo, os utilizados por alguns governantes.

Segundo Zacharias (2016, p. 20),

é necessário incluir no contexto escolar uma pedagogia que valorize e reconheça o universo multissemiótico e multimidiático marcado pelos ambientes digitais, uma pedagogia que não se restrinja à cultura do impresso. O leitor do nosso tempo é multimodal, logo incluir uma articulação entre o meio impresso e o digital (ZACHARIAS, 2016, p. 20).

Para atuar na educação, é necessário que o docente compreenda como os jovens se relacionam com o mundo e com as pessoas, consolidando, em tal processo, uma forma própria de enxergarem a si. A base de sustentação para a aprendizagem será através do afeto e do acolhimento, conforme analisou 
Wallon (2010). Wallon deixa bem claro a importância da relação no processo de afetividade. As relações interpessoais, ou seja, a relação entre pessoas, são muito importantes no processo de ensinoaprendizagem, a criança precisa ser amada para se auto afirmar e desenvolver do seu potencial na escola.

Nesse sentido, a formação de professores assume papel fundamental no desenvolvimento de práticas pedagógicas caracterizadas pela observação atenta dos jovens, pelo conhecimento e pelo respeito das especificidades da aprendizagem e, assim, pela intencionalidade e pela sistematicidade que permitem o movimento de aproximar o ideal (aquilo que o professor desejava) do real (aquilo que, efetivamente, os pequenos apresentam nas suas vivências).

Surgem, assim, políticas educacionais que tentam responder ou sinalizar para uma melhoria no ensino. Sobre o surgimento da BNCC, avalia Freitas (2018, p. 80):

[...] bases curriculares nacionais (tanto relativas ao que deve ser ensinado aos estudantes nas escolas quanto relativas à formação dos profissionais da educação) fornecem as competências e habilidades para "padronizar" o ensino e a aprendizagem; os testes (usualmente censitários) cobram a aprendizagem especificada pela base e fornecem, por sua vez, elementos para inserir as escolas em um sistema meritocrático de prestação de contas de seu trabalho, alimentando a competição entre professores e escolas. Neste processo, as escolas que "falham" nas metas ficam vulneráveis à privatização. O número de escolas que falham podem ser aumentado com o manejo e rigor das bases curriculares nacionais e dos testes nacionais. [...] a finalidade única dessa engenharia é criar condições para induzir a privatização da educação, estipulando metas que são difíceis de serem atingidas, nas condições atuais de funcionamento da educação pública, desmoralizando a educação pública e o magistério (FREITAS, 2018, p. 80).

A discussão de uma base curricular necessita ser debatida dentro do cenário público, pois não concordamos com a mercantilização da educação e com somente o olhar do gestor privado da educação no país. Dito isso, a base ignora, na sua discussão, a presença de comunidades e dos povos tradicionais no território brasileiro e busca tão somente formar profissionais para a sociedade industrial, logo o documento não democratiza o saber, mas reforça uma visão eurocêntrica de mundo e sociedade, submetendo assim os indivíduos aos interesses do mercado.

No que diz respeito ao ensino fundamental, como a base apresenta-se como um documento normativo que traça as aprendizagens essenciais para a educação básica, tais aprendizagens não envolvem apenas conteúdos, mas habilidades e competências que devem ser desenvolvidas ao longo de todos os anos escolares. Trata-se de um projeto de sociedade em que a escola deve contribuir para a formação cidadã. Suas diretrizes vêm exigindo alterações profundas nos currículos pedagógicos, 
materiais didáticos e formação de professores.

Com a implementação da BNCC, as principais mudanças no Ensino Fundamental - Anos finais vêm da necessidade de desenvolver, dentro das instituições de ensino, os conhecimentos, as habilidades, as atitudes e os valores essenciais para o século XXI. As mudanças próprias dessa fase da vida implicam a compreensão do adolescente como sujeito em desenvolvimento, com singularidades e com formações identitárias e culturais próprias, que demandam práticas escolares diferenciadas, capazes de contemplar suas necessidades e diferentes modos de inserção social.

Esse entendimento do adolescente como sujeito em desenvolvimento (evidenciada tanto pela BNCC quanto pelas Diretrizes Curriculares Nacionais) enfatiza a necessidade de a escola e o profissional da educação buscarem compreender e dialogar com as formas particulares de expressão dos estudantes nesta etapa de ensino. Isso relaciona-se, especialmente, ao envolvimento com a cultura e com a comunicação nos meios digitais, mas, na verdade, vai muito além disso, pois objetiva contribuir para o projeto de vida desse jovem.

Desde a década de 80 até hoje, observamos algumas mudanças, porém, ainda hoje, os alunos encontram-se mais distantes dos livros; ao que tudo indica, apenas práticas que considerem o gosto do aluno podem, de fato, contribuir para formar leitores anárquicos. Um leitor anárquico é aquele que sabe selecionar, dentre os textos que circulam socialmente, aqueles que podem atender às suas necessidades, conseguindo estabelecer as competências necessárias e adequadas de abordagem de tais textos. Sobretudo é capaz de ler as entrelinhas, identificando os elementos implícitos, estabelecendo relações interpessoais e realiza o seu direito ao contraditório, não só com o texto lido, mas, especialmente, com a sua posição social, política, histórica e ideológica, assim, esse leitor posicionase sobre o que lê de modo livre e corajoso (MENEZES, 2019).

Desse modo, tendo como base teórica para o ensino de literatura o letramento literário(COSSON, 2014), neste artigo, analisaremos os planos de aula formulados e aplicados em duas turmas de sextos anos. O objetivo, de modo geral, é escrutinar a aproximação da literatura e da música nessas aulas de ensino do gênero literário poema, avaliando de que modo se realiza a aproximação entre o ideal do texto literário e o real do consumo do alunado. A partir dos pressupostos teóricos de Cosson (2014), verificaremos qual é o lugar metafórico ocupado pela música nessa sequência de aulas e até que ponto ela serve a motivar e a intercambiar o interesse dos alunos e do professor no ensino de literatura.

\section{Pressupostos Teóricos para o Letramento Literário}

A sequência básica do letramento literário na escola, de acordo com Cosson (2014, p. 51), é organizada e pensada a partir de quatro passos: motivação, introdução, leitura e interpretação.

A motivação é a etapa que servirá para preparar o aluno a entrar no texto. Nesse sentido, 
as práticas de motivação são aquelas que estabelecem laços estreitos com o texto que se vai ler. Construir situações em que os alunos devem responder a uma questão ou posicionar-se diante de um tema é uma das formas mais usuais de construção da motivação.

A introdução é a fase de apresentação do autor e da obra; aqui, sugere-se que seja algo mais sucinto, uma vez que sua função é apenas permitir que o aluno receba a obra de modo positivo. Assim, a seleção criteriosa dos elementos que serão explorados, a ênfase em determinados aspectos dos paratextos e a necessidade de deixar que o aluno faça por si próprio outras materialidades da obra são características de uma boa introdução.

A leitura é a etapa a seguir e ela deve vir acompanhada de intervalos de leitura. Aqui, o professor solicita que o aluno leia um texto: se for pequeno, como poesia e conto, pode ser feito em sala de aula; caso seja uma obra maior, ela deve ser feita em casa ou em outro espaço, como na biblioteca. A leitura escolar precisa ser acompanhada porque ela tem uma direção, um objetivo a cumprir. Não é policiar o aluno, mas sim acompanhar. Durante o tempo de acompanhamento, ao docente cabe o papel de convidar os alunos a apresentar os resultados das suas leituras nos intervalos de leitura. Isso pode ser feito através de uma simples conversa, ou por meio da leitura de textos menores que tenham ligação com o texto maior, funcionando como uma focalização sobre o tema da leitura e permitindo que se teçam aproximações breves entre o que já foi lido e o novo texto. Ainda, pode-se solicitar a leitura conjunta de um capítulo ou trecho do capítulo para ser trabalhado estilisticamente em microanálise de recursos expressivos que interessem ao professor destacar. Os intervalos devem ser negociados com os alunos e avisados antecipadamente. Pelos intervalos, o professor realizará um diagnóstico no processo de leitura, dessa forma, o docente poderá resolver problemas ligados ao vocabulário e à estrutura composicional do texto, entre outras dificuldades ligadas à decifração.

A interpretação parte do cruzamento dos enunciados, que constituem as inferências, para chegar à construção do sentido do texto, dentro de um diálogo maior que envolve autor, leitor e comunidade. Duas são as etapas da interpretação: 1. Momento interior e 2. Momento externo. O momento interior é aquele que acompanha a decifração, palavra por palavra, página por página, capítulo por capítulo, e tem seu ápice na apreensão global da obra. A motivação, a introdução e a leitura são os elementos de interferência da escola no letramento literário. Do mesmo modo, a história de leitor do aluno, as relações familiares e tudo mais que constitui o contexto da leitura são fatores que vão contribuir de forma favorável ou desfavorável para esse momento interno. A interpretação é feita daquilo que somos no momento da leitura, por isso ela continua sendo um ato social. Já o momento externo é a concretização, a materialização da interpretação como ato de construção de sentido de uma determinada comunidade. Logo, ao dialogar e ao trocar as leituras, o aluno compreende estar numa coletividade e fortalece e amplia o horizonte de expectativas. A etapa da interpretação orientase registrar: se os alunos forem pequenos, com desenhos; se for adolescente, o professor pode solicitar uma resenha para o jornal da escola, por exemplo. Os murais escolares, os cenários, a troca de revistas

Revista Crioula - $\mathbf{n}^{\circ} \mathbf{2 6}$ - Relações entre literatura e música na produção de língua portuguesa

$2^{\circ}$ Semestre 2020 
e de livros usados, as feiras de livro nas escolas são sugestões para que o aluno externalize a reflexão sobre a obra lida e dialogue com sua comunidade.

A escolarização da literatura, aqui didatizada pela teoria de Cosson (2014), é discutida enquanto processo de formação de leitores por Menezes, Pagoto e Jacomel (2010). Segundo as autoras, o ensino de literatura deve partir, antes de mais nada, de um apreço e de uma fruição do texto literário, emancipando a arte da função de paratexto e a escolarização das amarras do conteudismo avaliativo. Ensinar literatura por ensiná-la, sem antes estabelecer um sentido entre o texto literário e o interesse do aluno, não forma leitores. É preciso, em rede, considerar todos os aspectos que formam leitores de literatura que não apenas a escola e que não apenas a obra, incluindo nesses aspectos o professor, os sujeitos que cercam esse aluno e, sobretudo, o próprio estudante de quem se quer fazer leitor.

Além disso, a leitura, assim como postulado pelas pesquisadoras, é a produção de sentidos. O leitor deve ser capaz não apenas de ver sentido naquilo que lê, considerado seu repertório, seu conhecimento de mundo e seu gosto particular, mas também produzir sentidos a partir daquilo que lê. Ao consumir o texto literário, deve ser capaz de imaginar as condições que figuraram a sua produção no tempo, no espaço e no contexto em que emergiu, mas deve também conseguir interpretá-lo em relação aos discursos que são seus contemporâneos, em relação à sua realidade enquanto sujeito.

Para que isso aconteça, afirmam Menezes, Pagoto e Jacomel (2010, p. 25) que "A batalha por uma melhoria com a leitura de literatura, seja ela, clássica ou não, na escola, depende de esforços conjuntos e de leis que se preocupem mais com o saber fazer". Ao professor, sujeito que intermedia o texto e o leitor, que intermedia a lei e o sujeito dessa lei, assim, cabe o lugar de conflito. Esse conflito que deve ser apaziguado em suas práticas docentes de escolarização e de letramento literário, práticas de ruptura e de formação efetiva de leitores capazes de produzir sentidos e de "saber fazer".

\section{A Música no Letramento Literário do Poema}

Em vista dos pressupostos teóricos levantados, escolhemos a análise de uma sequência de ensino do gênero poema. A sequência foi aplicada em uma escola de ensino fundamental particular de Maringá, no noroeste do estado do Paraná, a duas turmas da disciplina de Língua Portuguesa. No total, as turmas totalizam 51 (cinquenta e um) alunos.

Em vista do contexto de pandemia, o ensino remoto na instituição manteve o cronograma de aulas presenciais com a adaptação dos horários, reduzindo a hora-aula de 45 minutos para 30 minutos. Além de outros recursos, as aulas foram realizadas com o uso conciliado da plataforma de vídeo-chamadas Google Meet e a plataforma de sala de aula digital Google Sala de Aula para a postagem de materiais e de atividades.

O conteúdo da sequência, como antecipamos, foi o gênero poema, com o objetivo de apresentar 
as características textuais e discursivas desse gênero além de promover o letramento literário com o uso de textos de diversas autorias. A música, nesse sentido, foi um recurso motivacional de que se valeu o professor em momentos específicos dos planos de aula e das atividades por eles previstas. Vale ressaltar que, como diretriz institucional, todos os professores de todas as disciplinas da escola são encarregados de elaborar planos de ensino para todas as aulas ministradas, os quais são revisados pela supervisão escolar antes da aplicação aos alunos. Os planos de aula referentes a essa sequência foram escolhidos como corpus de análise para essa pesquisa, especificamente, os trechos da sequência que se referem à relação entre poema e música.

No total, foram doze aulas ministradas na sequência. De forma geral, analisamos que as quatro etapas do letramento literário propostas por Cosson (2014) não foram norteadoras para a elaboração macroscópica da sequência; assim, o objetivo geral identificado não foi o do letramento de um texto literário poético, mas a compreensão e a análise macroscópica desse gênero. A partir desse objetivo, objetivos específicos foram estabelecidos, a saber: diferenciar poema de poesia; compreender o contexto de produção e a relação entre autor e eu lírico; analisar e compreender o uso da linguagem figurada como recurso poético; identificar a organização textual geral do poema em verso e em estrofe, com a análise da rima como recurso rítmico; reconhecer o uso de recursos estilísticos como a aliteração e a assonância.

Destarte, o letramento literário ocorreu, de fato, em momentos específicos da sequência nos quais os poemas foram lidos. Sobre esses poemas, listam-se aqueles utilizados pelo professor em sua sequência: A bailarina, Cecília Meireles; Infância, Carlos Drummond de Andrade; $O$ menino azul, Cecília Meireles; A porta, Vinícius de Moraes; A lua foi ao cinema, Leminski; Ao pé de sua criança, Pablo Neruda; Barcos de Papel, Guilherme de Almeida; rio e de som a som ${ }^{3}$, Paulo Leminski; Este é o inverno, Clarice Pacheco. Além desses, citamos aqueles utilizados em uma das avaliações trimestrais da disciplina, O leão, Vinicius de Moraes, e O lagarto medroso, Cecília Meireles.

O uso dos poemas foi variado. Notamos que a fase da motivação foi realizada, no início da sequência, de forma mais evidente, para a leitura do poema Bailarina, de Cecília Meireles, com a projeção de fotografias de Gjon Mili (1904-1984), recurso utilizado também na fase da interpretação entre o poema e as fotografias. Já a fase da introdução foi repetida, assim como orienta a teoria, de forma sintética em cada um dos poemas apresentados. A fase da leitura de cada poema foi realizada com a oralização do texto, com os questionamentos orais e com os questionamentos escritos materializados em atividades, todos esses recursos individual ou coletivamente. Já a fase da interpretação foi executada em três momentos: na leitura do poema A bailarina, de Cecília Meireles, na leitura de Este é o inverno, de Clarice Pacheco, e na leitura da letra de Capitão Gancho, de Clarice Falcão, estabelecendo relações entre o título da música e a obra Peter Pan, de J. M. Barrie.

Além dos poemas, há as músicas que foram inseridas na sequência de aulas, a saber Pé com

3 Justificamos o uso de minúsculas no título dos dois poemas a fim de preservar a grafia original do autor. 
pé, Palavra Cantada, Capitão Gancho, Clarice Falcão, e Segue a seco, Marisa Monte. No plano, a primeira música é usada como recurso de motivação mas também de leitura no objetivo específico de compreensão da linguagem figurada como recurso poético. No quadro a seguir, o trecho do plano de aula que concerne a esse uso.

Quadro 1 - A música Pé com pé, do grupo Palavra Cantada, no plano de aula

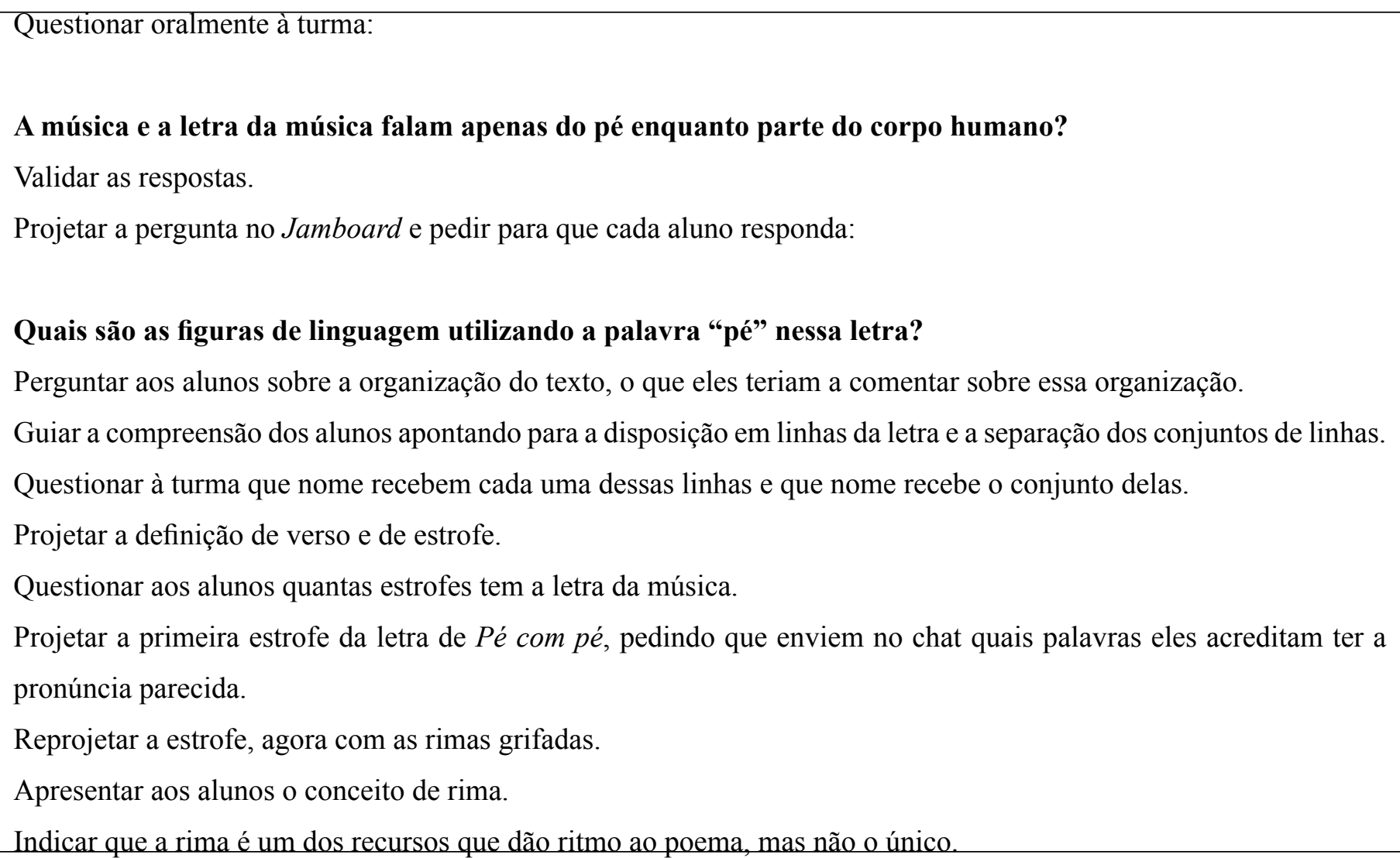

Fonte: Elaborado pelos autores.

Analisamos, aqui, uma primeira aproximação da literatura à música na compreensão da letra de música pelo recurso literário da linguagem figurada proposto à análise do poema. Nessa letra, vários são os usos figurados da linguagem em expressões que utilizam o substantivo "pé" em seu sentido conotativo. A partir dessa leitura, motivaram-se os alunos a pensarem a linguagem conotativa do poema, instrumentalizando-os às leituras futuras e, assim, conferindo-lhes recursos técnicos para o letramento literário.

A escolha musical, por sua vez, aponta para uma proximidade da composição com a realidade da infância do alunado em vista da temática e da ludicidade da letra. Segundo relato do professor, as discussões orais acerca da composição indicaram que alguns alunos de ambas as turmas já estavam familiarizados com o grupo. A escolha do grupo, inclusive, demonstra um novo ponto de aproximação 
entre literatura e música, uma vez que as composições originais do Palavra Cantada objetivam, justamente, a correlação entre o ritmo musical e a leitura poética.

Um segundo uso da música no plano foi o da composição Segue a seco, de Marisa Monte. A seguir, o quadro com o trecho que faz menção à ação docente.

\section{Quadro 2 - A música Segue a seco, de Marisa Monte, no plano de aula}

Projetar o clipe de Segue o seco - Marisa Monte e a letra da canção.

Questionar à turma:

Qual é a região mais seca do país?

Qual som se repete no título da canção?

Analisando a letra, esse som se repete ao longo da música?

Qual é o nome dessa figura de linguagem?

Que efeito tem o uso dessa figura de linguagem?

Orientar as respostas de forma a analisar o uso da aliteração no poema.

Fonte: Elaborado pelos autores.

Aqui, a música é usada também como contexto para cumprir um outro objetivo específico da sequência, o reconhecimento do uso de recursos estilísticos como a aliteração e a assonância Além da introdução e da leitura, houve, ainda segundo relato, a interpretação dessa letra com o poema Este é o inverno, de Clarice Pacheco. Notamos, novamente, uma aproximação entre o gênero poema e o gênero letra de música, utilizando a composição musical completa como motivação para análise e para leitura. Além disso, a interpretação da temática entre a canção de Marisa Monte e o poema de Clarice Pacheco, criando um paralelo entre literatura e música.

A música, enfim, apresenta-se em um terceiro momento do plano de ensino. É a composição Capitão Gancho, de Clarice Falcão. No quadro a seguir, há a menção da ação docente e da atividade em que a música foi analisada. 
Sintetizar, oralmente, as características estudadas do poema.

Questionar à turma se há alguma dúvida quanto ao estudo do poema.

Escutar à música Capitão Gancho, Clarice Falcão.

Ler a letra de música com os alunos.

Corrigir uma a uma as atividades.

Complementar a análise da letra e dos efeitos de sentido com a análise de demais versos ou aspectos.

Questionar aos alunos qual é a poesia dessa música.

Finalizar a análise traçando o paralelo entre os elementos da letra de música e do poema.

Fonte: Elaborado pelos autores.

Nesse plano, fica mais evidente a aproximação entre música e poema, explícita até na ação docente e na fala do professor. A atividade, aplicada como tarefa de casa, foi composta por exercícios que retomaram todos os objetivos específicos estabelecidos para o plano. Dessa forma, a retomada dos conteúdos estudados acerca do poema e a pergunta final, relacionando poesia e poema, dão conta dessa evidência. Não obstante, a correlação feita entre os elementos da letra de música e do poema aproximam as duas artes em suas similaridades. Oralmente, segundo relato do professor, foi realizada a explicação da origem histórica do gênero poema pela etimologia do termo "lírico", relacionando sua origem grega à musicalização das letras de música no presente histórico, o que contribui à aproximação repetida e analisada nos planos.

Uma etapa subsequente às aulas acerca do gênero poema foi a de produção textual de um poema concreto. Entendemos que o processo de escolarização da literatura não prevê a formação de autores de literatura (o que, por si só, configura uma nova e profícua reflexão da qual nos abstemos aqui). No entanto, como pontuam Menezes, Pagoto e Jacomel (2010), ler literatura é ver nela e produzir sentidos a partir dela. Selecionamos, assim, cinco produções de alunos a fim de ilustrar uma possível emancipação do papel de leitor do papel de aluno em processo de avaliação.

Desse modo, nas produções selecionadas, longe de avaliarmos criticamente os textos literários materializados, pretendemos refletir, nas considerações que finalizam nosso trabalho, sobre os efeitos do letramento literário nos alunos e se, de fato, a escolarização da literatura é capaz de, em acordo com os pressupostos teóricos e por meio de práticas que buscam aproximar o literário da realidade dos alunos, humanizá-los.

Os encaminhamentos didáticos para essa produção começaram com o planejamento de um texto a partir de perguntas que direcionassem o aluno à produção. Nessas perguntas, tiveram de escolher algo do cotidiano, um substantivo simples, sobre o qual quisessem escrever. A partir disso, foram convidados a caracterizar esse substantivo, a relacionar a ele suas ações e a pensar em sons que 
remetessem a ele. Na aula seguinte, coube aos alunos produzir um poema sobre esse ser ou objeto do cotidiano a partir de sua perspectiva individual, sua percepção particular do mundo. A atividade foi finalizada, em um terceiro momento, quando, após produzidos os poemas, os alunos reescreveram-nos, transformando-os em poema concreto, utilizando recursos visuais e sonoros (as onomatopeias pensadas na primeira atividade) para isso. Cabe o comentário aqui de que as produções não passaram por revisão ortográfica no intuito de evitar a gramaticalização da produção criativa. Uma amostra dos resultados são os poemas a seguir:

Imagem 1 - Poema do aluno A

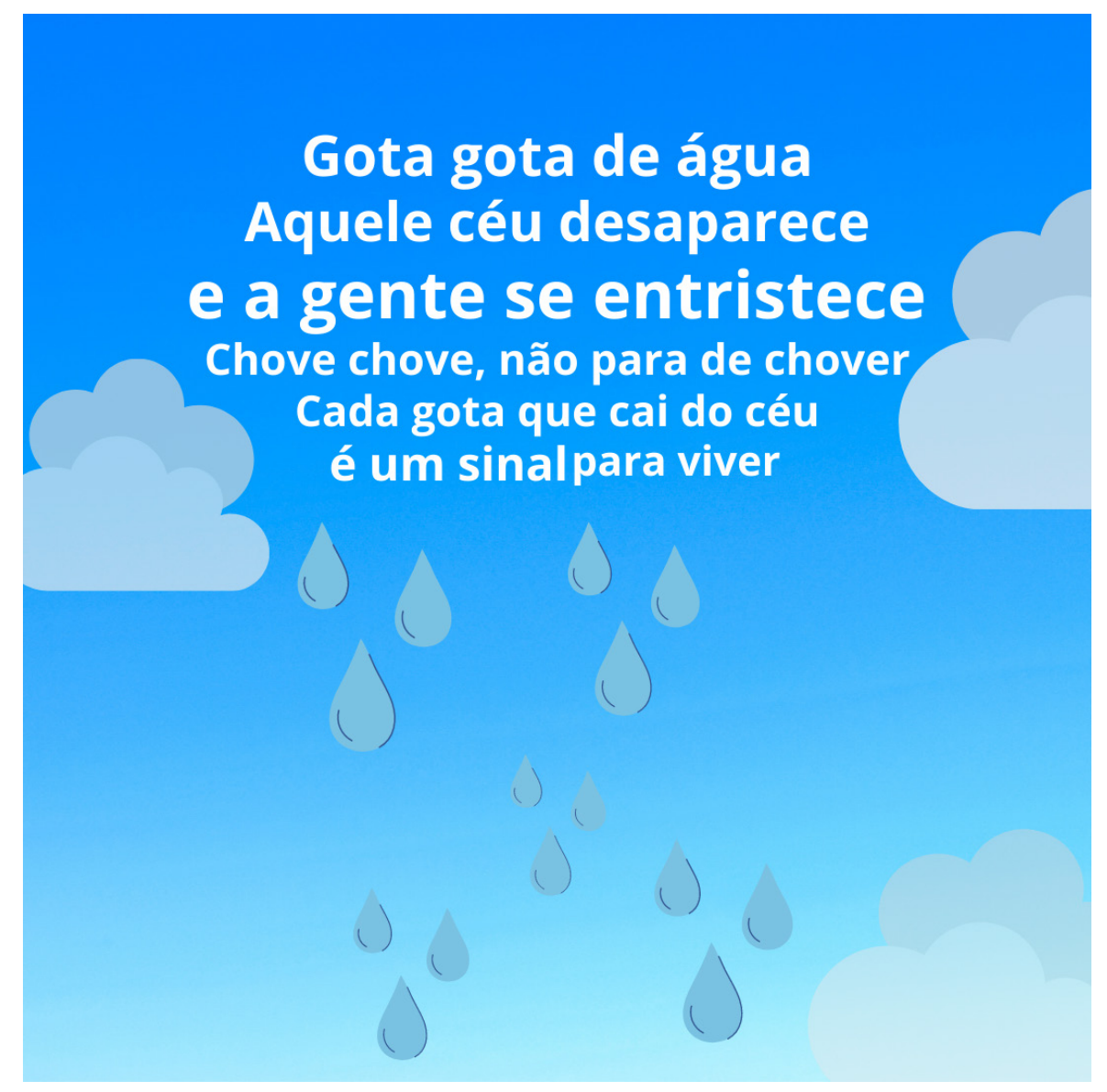

Fonte: Acervo dos autores. 
Imagem 2 - Poema do aluno B

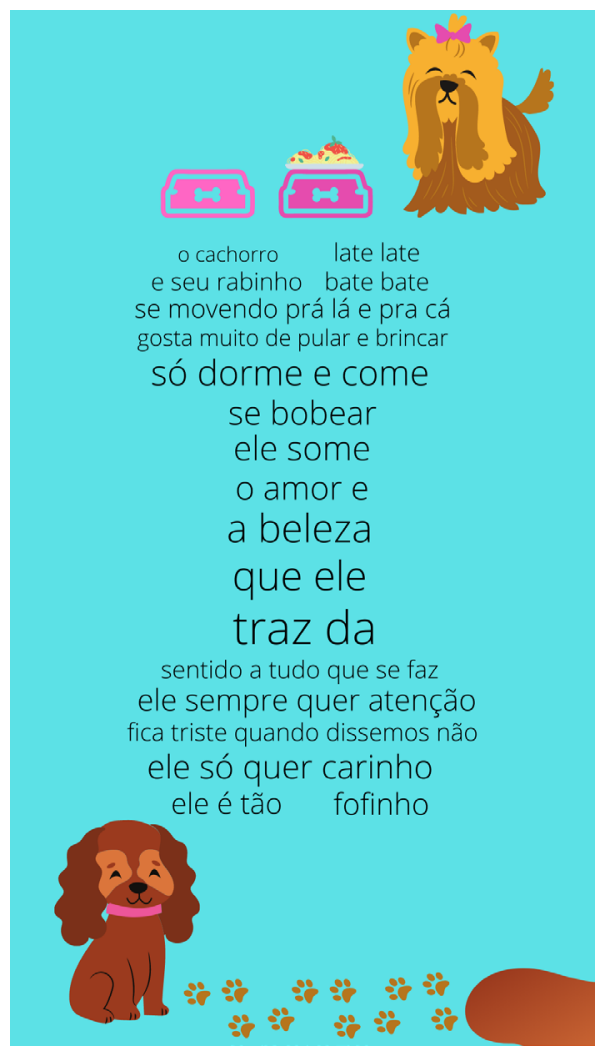

Fonte: Acervo dos autores.

Imagem 3 - Poema do aluno C

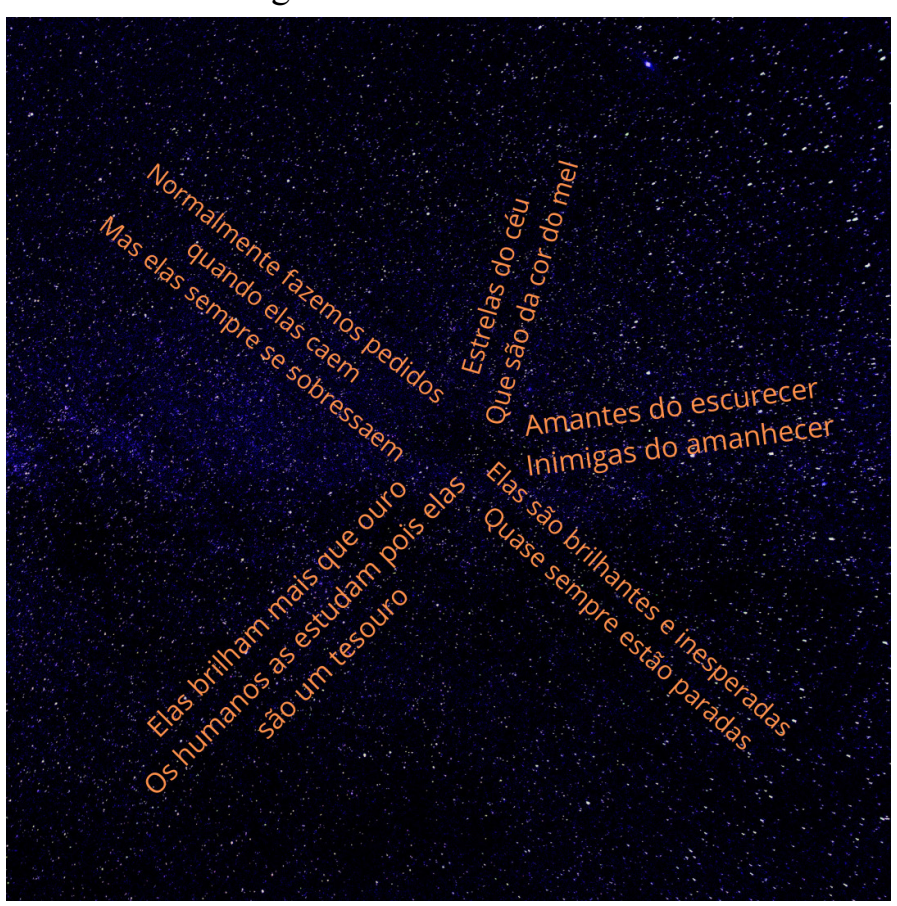

Fonte: Acervo dos autores.

Imagem 4 - Poema do aluno D 


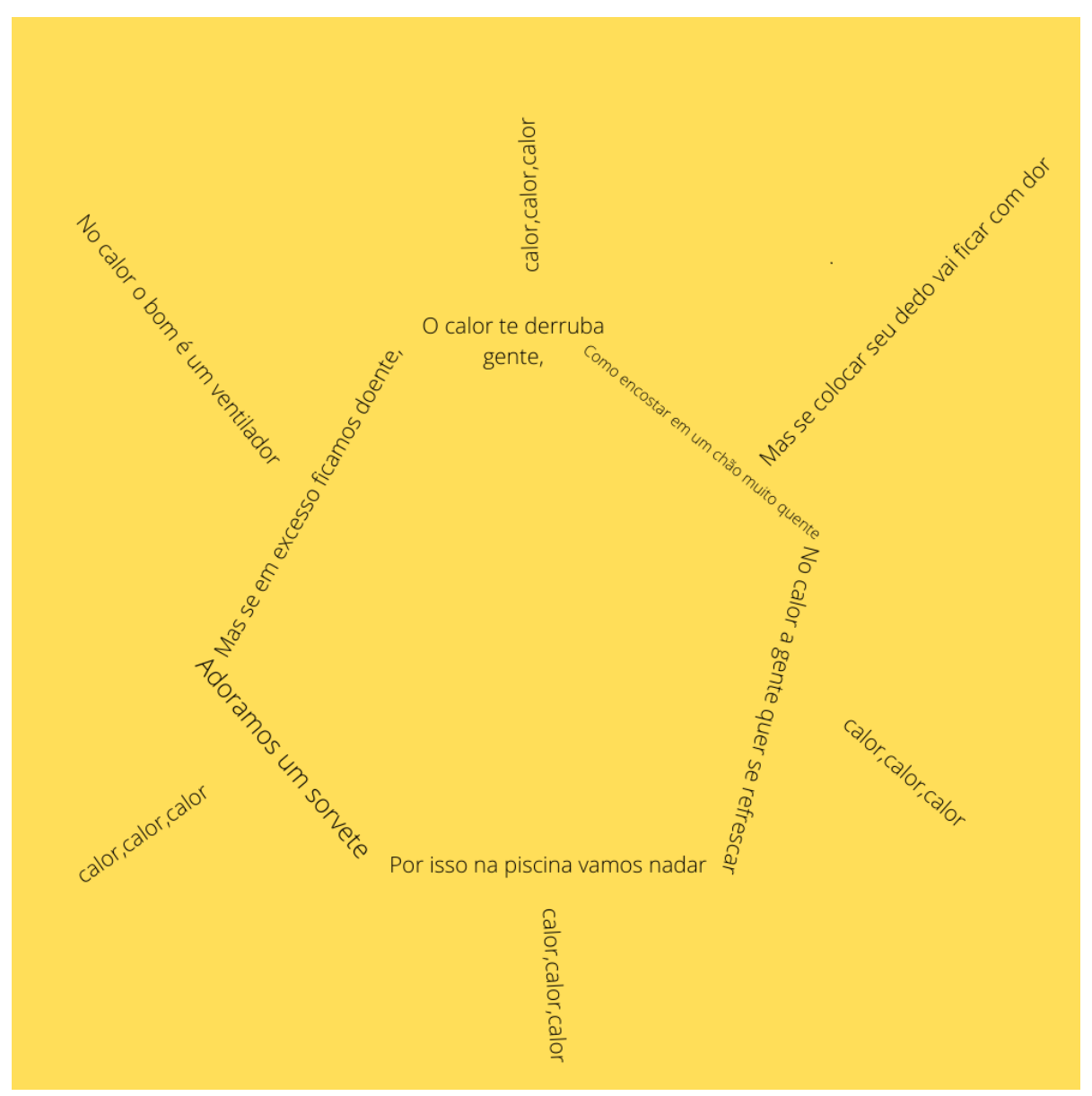

Fonte: Acervo dos autores.

Imagem 5 - Poema do aluno E

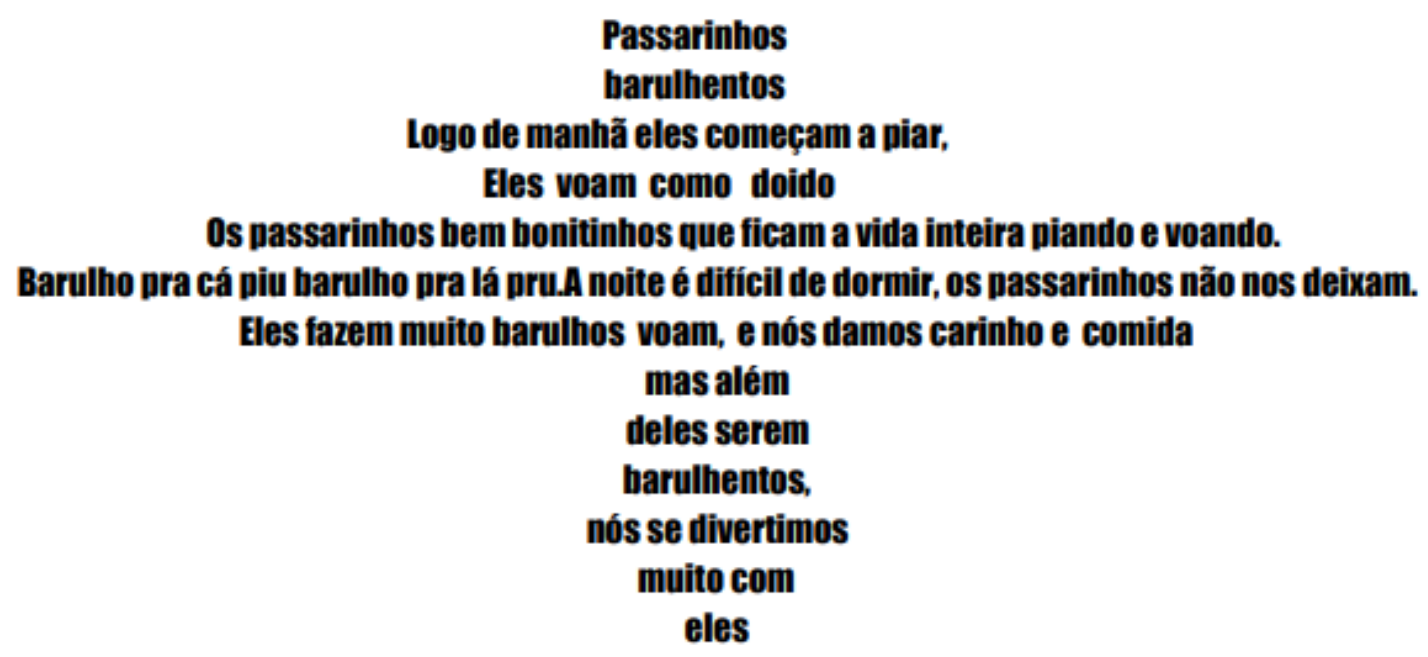

Fonte: Acervo dos autores.

Revista Crioula - nº 26 - Relações entre literatura e música na produção de língua portuguesa 


\section{Considerações Finais}

O objetivo desse trabalho, a priori, foi o de analisar a relação possível entre a música e a literatura em contexto escolar. Pautados em uma prática de ensino real e efetivada em sala com alunos do sexto ano do Ensino Fundamental II, o que verificamos foi que o encontro não apenas é possível, como é realizado. Em vista das similaridades entre as duas expressões artísticas, similaridades essas justificadas, inclusive, pela origem em comum dos gêneros letra de música e poema, notou-se uma tentativa de escolarizar, com sucesso, a literatura a fim de que os alunos vissem nessa arte algum sentido mais concreto e familiar. Essa familiaridade poder-se-ia justificar por diversas razões que não cabem aqui; interessa-nos pontuar que a música é uma arte que tem vencido o tempo e reformuladose no gosto massificado muito mais que a poesia.

Nos planos de aula, nota-se como ela é um caminho pelo qual se convida os alunos a adentrarem nas reflexões temáticas, organizacionais e estilísticas da literatura, apreendendo no texto escrito também a musicalidade perdida do gênero lírico. É por meio dela também que os alunos são motivados a fazer a leitura literária e levados a interpretar os textos poéticos com outros textos, com outros temas e com sua própria realidade. $\mathrm{O}$ encontro, assim, efetiva-se entre literatura e música na escola.

A escolarização da literatura, contudo, enfrenta desafios: de um lado, o ensino é orientado tanto quanto cerceado pelas diretrizes curriculares em todos os níveis institucionais do país, estabelecendo uma lista de competências e de cobranças aos quais os dois sujeitos do processo de ensino, professor e aluno, estão submetidos. Essa cobrança transpassa a prática docente e nota-se no conteudismo e na instrumentalização em detrimento do consumo e da fruição. Nos planos, isso fica evidente quando o ensino é pautado pelos objetivos que precedem e prescindem o texto literário e quando a música, embora excelente motivadora, não é apreciada em sua própria forma e conteúdo, mas como paratexto.

Nesse contexto, vislumbram-se as múltiplas escolhas do professor quanto aos textos literários e as múltiplas tentativas de, efetivamente, letrar os alunos para a arte da literatura, seja por meio da música, da fotografia, do videoclipe ou de qualquer outro gênero que consumam. Isso demonstra o outro lado do desafio, a prática docente. Uma prática docente que tem de buscar, ao mesmo tempo, cumprir com as obrigações e ensinar o poder libertário da literatura; instrumentalizar os alunos à leitura literária fora da sala de aula e possibilitar o apreço e o consumo da literatura enquanto fruição da arte e a humanização do leitor em um público que não consome, via de regra, o que é entendido como literatura.

É nesse ponto que a produção de texto emerge dessa prática como uma possibilidade de libertação: ao serem convidados a olhar para a realidade circundante com os olhos da poesia, a se colocarem no lugar de um(a) poeta(isa), a refletirem sobre como se sentem em relação às coisas banais, a expressarem esse sentir em uma linguagem conceptual, convidam-se esses alunos a consumirem 
a literatura não do seu ponto de vista individual do contemporâneo datado, mas do ponto de vista universal e, ainda, particular e único de ser humano que sente o mundo. Convidam-se esses alunos a ver um sentido na literatura e a produzir, a partir dela, novos sentidos.

Nesse conflito silencioso entre a literatura enquanto arte e a literatura enquanto pretexto, o que concluímos é que a escolarização do texto literário é possível se considerado o aluno enquanto leitor contemporâneo e enquanto ser humano que precisa, primeiramente, ser assim visto pelo professor. $\mathrm{O}$ encontro entre música e literatura, assim como entre cinema e literatura, entre HQ e literatura, entre jogos eletrônicos e literatura, existe e deve ser arranjado em sala de aula. Antes, porém, um encontro possível e necessário é o do aluno com a sua posição de leitor - e não de qualquer leitor: um leitor capaz de ver sentido no texto literário, de ver sentido do texto literário em sua vida e de produzir sentidos próprios a partir da leitura do literário; enfim, um aluno leitor anárquico.

\section{Referências Bibliográficas}

BRASIL. Ministério da Educação. Site institucional. O que é a Base Nacional Comum Curricular? Disponível em: http://basenacionalcomum.mec.gov.br/\#/site/base/o-que>. Acesso em: 17 out. 2020.

. Ministério da Educação. Base Nacional Comum Curricular. 2a Versão Revista. Disponível em: http:// basenacionalcomum.mec.gov.br/documentos/bncc-2versao.revista.pdf. Acesso em: 17 out. 2020.

CANDIDO, Antonio. Direitos Humanos e Literatura. In: FERSTER, A. C. Ribeiro. Direitos humanos e... São Paulo: Brasiliense, 1989.

CEREJA, William Roberto. O dialogismo como procedimento no ensino de Literatura. In: . Ensino de

Literatura: uma proposta dialógica para o trabalho com literatura. São Paulo: Atual, 2005.p. 162 - 195

COSSON, Rildo. Letramento Literário: teoria e prática. São Paulo: Contexto, 2014.

FREITAS, Luiz Carlos de. A reforma empresarial da educação: nova direita, velhas ideias. São Paulo: Expressão Popular, 2018.

LEAHY-DIOS, Cyana. Educação literária como metáfora social: desvios e rumos. Rio de Janeiro: Ed. UFF, 2000.

MENEZES, Juliana Alves Barbosa. Ensino de literatura e vestibular: que leitor espera a Universidade Estadual de Maringá e o que recebe. Dissertação (Mestrado) - Universidade Estadual de Maringá, Programa de Pós-Graduação 
em Letras, Maringá, 2008.

Educação Literária no Ensino Médio: estudo de caso das escolas paranaenses. 2019. Tese (Doutorado) Universidade Estadual Paulista, Programa de Pós-Graduação em Letras, Assis, 2019.

MENEZES, Juliana Alves Barbosa; PAGOTO, Cristian; JACOMEL, Mirele Carolina Werneck. Escolarização da poesia clássica. In: Interletras, Dourados: 2: 11-27, 2010.

OLIVEIRA, Gabriela Rodella. O professor de português e a literatura: relações entre formação, hábitos de leitura e prática de ensino. Dissertação (Mestrado) - Faculdade de Educação, USP, São Paulo, 2008.

ROCCO, Maria Thereza Fraga. Literatura-Ensino: uma problemática. 2.ed. São Paulo: Ática, 1992.

VIEIRA, Alice. O prazer do texto: perspectivas para o ensino de literatura. São Paulo: EPU, 1990

WALLON, Henri. A evolução psicológica da criança. São Paulo: Martins Fontes, 2010.

ZACHARIAS, Valéria Ribeiro de Castro. Letramento digital: desafios e possibilidades para o ensino. In: Tecnologias para aprender. COSCARELLI, Carla Viana (Org). São Paulo: Parábola Editorial, 2016. P. 15-26. 